\title{
New-onset atrial fibrillation and associated outcomes and resource use among critically ill adults-a multicenter retrospective cohort study
}

\author{
Shannon M. Fernando ${ }^{1,2^{*}}$ (D) Rebecca Mathew ${ }^{1,3}$, Benjamin Hibbert ${ }^{3}$, Bram Rochwerg $^{4,5}$, Laveena Munshi ${ }^{6,7}$, \\ Allan J. Walkey ${ }^{8,9}$, Morten Hylander Møller ${ }^{10}$, Trevor Simard ${ }^{3}$, Pietro Di Santo ${ }^{3}$, F. Daniel Ramirez ${ }^{3,11,12}$, \\ Peter Tanuseputro ${ }^{13,14,15,16}$ and Kwadwo Kyeremanteng ${ }^{1,13,15,17}$
}

\begin{abstract}
Background: New-onset atrial fibrillation (NOAF) is commonly encountered in critically ill adults. Evidence evaluating the association between NOAF and patient-important outcomes in this population is conflicting. Furthermore, little is known regarding the association between NOAF and resource use or hospital costs.

Methods: Retrospective analysis (2011-2016) of a prospectively collected registry from two Canadian hospitals of consecutive ICU patients aged $\geq 18$ years. We excluded patients with a known history of AF prior to hospital admission. Any occurrence of atrial fibrillation (AF) was prospectively recorded by bedside nurses. The primary outcome was hospital mortality, and we used multivariable logistic regression to adjust for confounders. We used a generalized linear model to evaluate contributors to total cost.

Results: We included 15,014 patients, and 1541 (10.3\%) had NOAF during their ICU admission. While NOAF was not associated with increased odds of hospital death among the entire cohort (adjusted odds ratio [aOR] 1.02 [95\% confidence interval [CI] 0.97-1.08]), an interaction was noted between NOAF and sepsis, and the presence of both was associated with higher odds of hospital mortality (aOR 1.28 [95\% Cl 1.09-1.36]) than either alone. Patients with NOAF had higher total costs (cost ratio [CR] 1.09 [95\% Cl 1.02-1.20]). Among patients with NOAF, treatment with a rhythmcontrol strategy was associated with higher costs (CR 1.24 [95\% Cl 1.07-1.40]).
\end{abstract}

Conclusions: While NOAF was not associated with death or requiring discharge to long-term care among critically ill patients, it was associated with increased length of stay in ICU and increased total costs.

Keywords: Atrial fibrillation, Critical care, Intensive care unit, Resource utilization, Costs

\section{Introduction}

Atrial fibrillation (AF) is the most common cardiac dysrhythmia, with a lifetime risk of 1 in 4 among older adults [1]. Development of AF has been associated with stroke, myocardial infarction, heart failure, and death [2]. In the intensive care unit (ICU), patients often present with pre-

\footnotetext{
*Correspondence: sfern014@uottawa.ca

${ }^{1}$ Division of Critical Care, Department of Medicine, University of Ottawa, Ottawa, ON, Canada

${ }^{2}$ Department of Emergency Medicine, University of Ottawa, Ottawa, ON, Canada

Full list of author information is available at the end of the article
}

existing AF; however, some ICU patients may develop new-onset AF (NOAF) in the context of critical illness [3]. Unlike AF seen in non-critically ill patients, NOAF is often thought to be a consequence of critical illness pathophysiology and treatment, including inflammation, electrolyte disturbances, or proarrhythmic medications, namely vasopressors and inotropes [4]. Incidence of NOAF in the general ICU varies markedly; however, most studies suggest that $10-15 \%$ of patients will develop this complication during their ICU stay [3-5].

The clinical importance of critical illness-associated NOAF is a matter of ongoing uncertainty [4]. AF in and 
of itself may contribute to clinical decompensation through hemodynamic compromise [6]. Alternatively, NOAF may simply represent a marker of increased illness severity, and may identify patients at increased risk of death without acting causally to worsen prognosis. Some cohort studies have identified an independent association between NOAF and mortality [7-9], while others have not $[5,10]$. Whether this relationship is seen among all critically ill patients, or limited to select subgroups, is unknown. Furthermore, the factors associated with death among patients with NOAF are unknown.

Equally important is the relationship between NOAF, and subsequent ICU resource use and costs $[11,12]$. Since the ICU is a major source of hospital expenditure, considerable effort has been dedicated to understand the contributors to cost, in order to drive policy and optimize resource utilization [13]. With regard to NOAF, little is known regarding the degree of impact on cost expenditures. We primarily sought to evaluate the association between NOAF and outcomes, resource utilization, and costs among critically ill adult patients. Given the prognostic importance of NOAF among patients with sepsis $[14,15]$, we secondarily aimed to evaluate the association between incidence of NOAF and associated outcomes and resource utilization among critically ill patients with suspected infection, sepsis, and septic shock.

\section{Materials and methods}

We obtained ethics approval for this study from the Ottawa Health Science Network Research Ethics Board (protocol 20160570-01H).

\section{Study design, setting, and subjects}

We studied ICU patients from two hospitals within the Ottawa Hospital network (Ottawa, ON). These hospitals have approximately 2500 combined ICU admissions per year. These are combined medical and non-cardiac surgical ICUs. We retrospectively examined prospectively collected data from the Ottawa Hospital Data Warehouse, a health administrative database used in previous studies [16-19]. From hospital admission, data is gathered daily from each patient and stored in the Data Warehouse. Data quality assessments are executed routinely, and quality-assurance initiatives are conducted regularly to ensure completeness and accuracy.

We included all consecutive patients $\geq 18$ years of age, admitted to one of the two ICUs between January 2011 and December 2016. Sample size was determined pragmatically, on the basis of available patients in the Data Warehouse. We also examined pre-specified subgroups of patients, including those with suspected infection, sepsis, and septic shock, as based on the Third International Consensus Definitions for Sepsis and Septic Shock (Sepsis-3) [20-22]. "Suspected infection" was defined as concomitant administration of oral or parenteral antibiotics, and sampling of body-fluid cultures, as performed previously [16, 23], and in keeping with the Sepsis-3 definitions [20]. "Sepsis" was defined as suspected infection and an increase in the Sequential Organ Failure Assessment (SOFA) score by greater than 2 points [20, 21]. Finally, "septic shock" was defined by sepsis in addition to initiation of vasopressors or a serum lactate $\geq 2.0 \mathrm{mmol} / \mathrm{L}[20,22]$.

\section{Data collection}

We obtained all data from the Ottawa Hospital Data Warehouse. We abstracted demographic data, comorbidities, Elixhauser Comorbidity Score [24], and Multiple Organ Dysfunction Score (MODS) [25] at the time of ICU admission. The Elixhauser Comorbidity Score is generated from comorbidities stored in the Data Warehouse, and the association between this index and hospital mortality has been previously validated in our database [26]. The "most responsible diagnosis" was recorded at death or discharge, based upon International Classification of Diseases, Version 10 (ICD-10, July 2015). We also noted whether there was presence of a "No cardiopulmonary resuscitation (CPR)" directive at the time of ICU admission. We collected outcome data from admission until either the point of discharge from hospital or hospital death.

We determined patient costs using the case-costing system of the Ottawa Hospital Data Warehouse, as done previously [17, 23, 27]. Total hospital costs include both direct and indirect sources. Direct costs refer to all hospital expenses with fee codes linked to the patient identifier. Indirect costs refer to any overhead operational fees associated with provided service. The Ottawa Hospital uses a standardized case-costing methodology, developed by the Ontario Case Costing Initiative, and based upon the Canadian Institute for Health Information Management guidelines [28]. Costs were indexed to 2018 Canadian Dollars using consumer price indices [23, 27].

\section{Outcomes}

The primary outcome was hospital mortality. Secondary outcomes included discharge directly from hospital to long-term care (among survivors to hospital discharge originally from home), hospital readmission within 30 days of hospital discharge among survivors, ICU length of stay (LOS), hospital LOS, resource utilization (including invasive and non-invasive mechanical ventilation, and renal replacement therapy), and total hospital costs.

\section{Screening for atrial fibrillation}

For each patient, the occurrence of any AF was prospectively recorded by bedside nurses for the purposes of quality assurance. The date and time of AF, as captured by the bedside nurse, was stored in the Data 
Warehouse. Patients identified through this method were then evaluated by a single investigator (SMF), to confirm the diagnosis. Since there is no consensus definition for NOAF [4], we followed pre-existing definitions from the literature $[7,8]$. NOAF was defined as either (1) $\mathrm{AF} \geq 1 \mathrm{~h}$ in duration, as noted by bedside telemetry (routinely evaluated in charts where electrocardiograms were not completed); (2) $\mathrm{AF}<1 \mathrm{~h}$ in duration, but captured on electrocardiogram; or (3) AF initiating pharmacologic therapy or electrical cardioversion. All bedside ECGs, along with final interpretation by an attending cardiologist are stored in patient records. "Sustained" AF was defined as failure to convert to sinus rhythm $24 \mathrm{~h}$ following the onset of any pharmacological treatment or electrical cardioversion. We excluded patients with a previously documented or known history of AF, as determined at the time of hospital admission and stored in the Data Warehouse.

\section{Statistical analysis}

We performed all statistical analyses using $\mathrm{R}$ (version 3.3.3) and IBM SPSS (version 24.0). We present data as mean values, with standard deviation (SD), or medians, with interquartile range (IQR), where appropriate. Student's $t$ test (parametric values), Mann-Whitney test (non-parametric values), and $\chi^{2}$ (for categorical values) were performed to determine between-group differences. In keeping with existing guidelines, we did not perform pairwise comparisons of baseline characteristics [29]. To adjust for measured confounders in the association between new-onset AF and outcomes of interest, we followed recommendations for observational studies in the critically ill [30]. As per these recommendations, confounders were determined a priori, on the basis of their likelihood of influencing both the presence of NOAF and mortality and not acting as mediators or colliders in the association between AF and mortality, as based upon existing clinical knowledge evaluating the association between NOAF and mortality in critically ill patients [3, 4]. In accordance with these recommendations [30], we used multivariable logistic regression modeling to adjust for important continuous (age, MODS at ICU admission, Elixhauser comorbidity index) and categorical (sex, individual comorbidities, "No-CPR" directive on admission, location prior to ICU admission, and most responsible diagnosis) variables. As recommended, variables on the causal pathway and potentially contributing to NOAF (e.g., vasoactive medications) were not included [30]. We evaluated for possible synergy between NOAF and sepsis through the use of an interaction term in the primary model, as performed previously [23]. If a statistically significant interaction term was found between NOAF and sepsis, we then represented this with a four-level categorization. We assessed variation in total hospital costs using a multivariable generalized linear model with gamma distribution and log link [31, 32]. We present adjusted odds ratios (aORs) and cost ratios (CRs) with 95\% confidence intervals. A $P$ value of $\leq 0.05$ was considered statistically significant.

\section{Results}

A total of 17,173 patients were admitted to the participating ICUs from 2011 to 2016 (Fig. 1). Of these, 2105 patients $(12.3 \%)$ had a known or documented history of AF prior to ICU admission, and were excluded. A further 54 patients $(0.4 \%)$ were excluded because of missing outcome data.

We included 15,014 patients in the analyses. Of these patients, $1541(10.3 \%)$ had NOAF while in the ICU. Baseline characteristics of patient with and without NOAF are shown in Table 1. NOAF patients were older (mean age 64.7 years vs. 58.5 years), had higher severity of illness (mean MODS 5.3 vs. 4.2), and higher comorbidity burden.

Patient outcomes are depicted in Table 2. Median time from hospitalization to development of NOAF was 1 day (IQR 1-3), and 345 (22.4\%) of NOAF patients had sustained AF lasting longer than $24 \mathrm{~h}$. Multivariable logistic regression analyses examining in-hospital mortality among the entire cohort, and among subgroups with suspected infection $(n=4837$, Table 3$)$, sepsis $(n=1944$, $40.2 \%$ of "suspected infection" population), and septic shock ( $n=1286,66.2 \%$ of "sepsis" population) are included in Additional files 1, 2, and 3: Tables S1-S3, respectively). Following adjustment for confounding variables, NOAF was not associated with higher hospital mortality among all ICU patients (aOR 1.02 [95\% CI $0.97-1.08]$ ). However, NOAF was associated with higher hospital mortality among ICU patients with suspected infection (aOR 1.21 [95\% CI 1.08-1.37]), sepsis (aOR 1.24 [95\% CI 1.10-1.39]), and septic shock (aOR 1.28 [95\% CI 1.14-1.44]). A statistically significant interaction was seen between NOAF and presence of sepsis, and the presence of both was associated with higher odds than either alone (Additional file 4: Table S4). No difference was seen with regard to disposition to home among survivors (aOR 0.95 [95\% CI 0.88-1.09]), readmission to ICU during hospitalization (aOR 1.04 [95\% CI 0.951.11]), or hospital readmission within 30 days of discharge (aOR 1.08 [95\% CI 0.87-1.19]). Patients with NOAF had prolonged median ICU LOS (7 days vs. 6 days, $P<0.001)$ and median total hospital LOS (14 days vs. 12 days, $P<0.001)$. Among patients with NOAF, factors associated with increased risk of hospital mortality included increasing age, increased MODS score, history of CHF (as identified in the Data Warehouse), and sustained AF (Additional file 5: Table S5). 


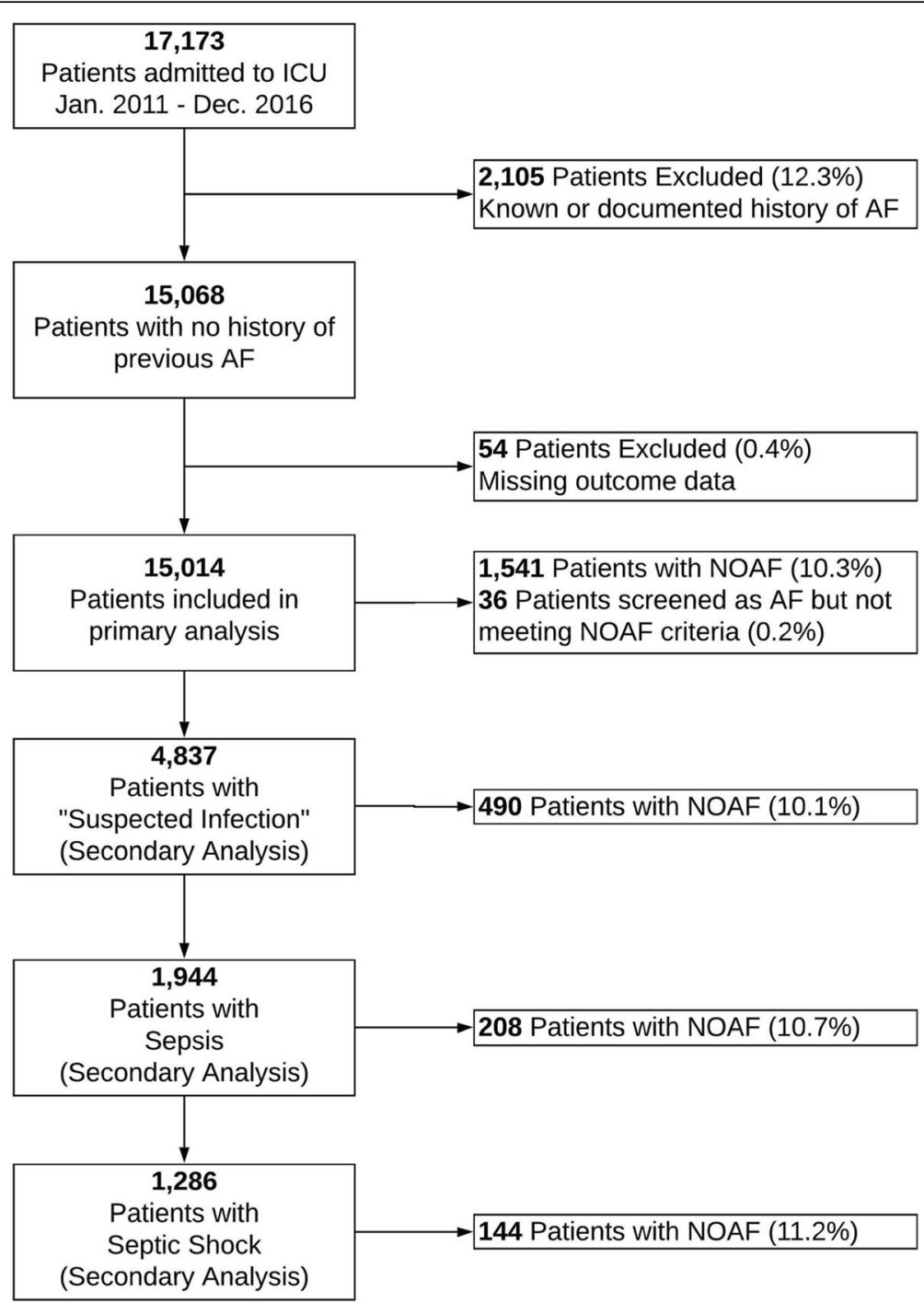

Fig. 1 Study flow diagram. AF, atrial fibrillation; ICU, intensive care unit; NOAF, new-onset atrial fibrillation

Comparisons of resources used between patients with and without AF are shown in Table 4. No differences were seen in the use of invasive $(54.7 \%$ in those with NOAF vs. $52.8 \%$ in those without NOAF, $P=0.16$ ) or non-invasive ventilation $(16.6 \%$ in those with NOAF vs. $17.5 \%$ in those without NOAF, $P=0.38)$. Vasoactive medication use was higher among patients with $\operatorname{NOAF}(64.3 \%$ vs. $61.2 \%, P=$ 0.02). In terms of treatment strategy for NOAF, 747 (48.5\%) patients received antiarrhythmic medical therapy (i.e., amiodarone, procainamide, or flecainide), while 644 (41.8\%) received therapy with a beta-blocker, calcium channel blocker, or digoxin. A total of 128 patients (8.3\%) received a combination of the above therapies.

Finally, comparisons of patient costs between patients with and without NOAF are shown in Table 5. Mean total costs were higher among NOAF patients $(\$ 50,799$ vs. $\$ 41,832, P<0.001)$, as were mean total ICU costs
( $\$ 41,303$ vs. $\$ 28,298, P<0.01)$. Total cost per survivor for patients with NOAF was $\$ 81,120$, as compared to $\$ 59,710$ for patients without NOAF. Presence of NOAF in our ICU cohort was a significant predictor of total hospital costs (CR 1.09 [95\% CI 1.02-1.21], Additional file 6: Table S6). Among patients with NOAF (Additional file 7: Table S7), significant predictors of total hospital costs include total hospital or ICU LOS, use of invasive mechanical ventilation or renal replacement therapy, and use of antiarrhythmic medical therapy (as compared to beta-blocker, calcium channel blocker, or digoxin treatment).

\section{Discussion}

We identified NOAF in $10.3 \%$ of critically ill adults, in keeping with known prevalence rates [4]. We found no association between NOAF and increased hospital 
Table 1 Characteristics of ICU patients $(n=15,014)$ with and without new-onset atrial fibrillation (NOAF)

\begin{tabular}{|c|c|c|}
\hline Characteristic & New-onset atrial fibrillation $(n=1541)$ & No atrial fibrillation $(n=13,473)$ \\
\hline Age, years, mean (SD) & $64.7(17.6)$ & $58.7(12.2)$ \\
\hline Male, $n(\%)$ & $854(55.4)$ & $7114(52.8)$ \\
\hline ICU MODS, mean (SD) & $5.3(2.4)$ & $4.2(2.7)$ \\
\hline \multicolumn{3}{|l|}{ Comorbidities } \\
\hline Congestive heart failure & $223(14.5)$ & $869(6.4)$ \\
\hline Peripheral vascular disease & $124(8.0)$ & $418(3.1)$ \\
\hline Hypertension & $525(34.1)$ & $3341(24.8)$ \\
\hline Chronic obstructive pulmonary disease & $176(11.4)$ & $1414(10.5)$ \\
\hline Diabetes mellitus & $427(27.7)$ & $3422(25.4)$ \\
\hline Chronic kidney disease & $129(8.4)$ & $1037(7.7)$ \\
\hline Liver disease & $63(4.1)$ & $528(3.9)$ \\
\hline Malignancy & $221(14.3)$ & $1874(13.9)$ \\
\hline Alcohol misuse & $81(5.3)$ & $732(5.4)$ \\
\hline Psychosis & $23(1.5)$ & $139(1.0)$ \\
\hline Depression & $41(2.7)$ & $288(2.1)$ \\
\hline Elixhauser Comorbidity Score, mean (SD) & $5.3(4.1)$ & $4.1(3.7)$ \\
\hline Daytime ICU admission (0800-1700), n (\%) & $932(60.5)$ & $8472(62.9)$ \\
\hline \multicolumn{3}{|l|}{ Location prior to ICU admission, $n$ (\%) } \\
\hline Emergency department & $653(42.4)$ & $5930(44.0)$ \\
\hline Hospital wards & $501(32.5)$ & $4374(32.5)$ \\
\hline Operating room & $78(5.1)$ & $754(5.6)$ \\
\hline Peripheral hospital & $309(20.1)$ & $2415(17.9)$ \\
\hline Previous ED visits, mean (SD) ${ }^{a}$ & $2.3(2.5)$ & $2.3(2.2)$ \\
\hline Previous ICU admissions, mean (SD) ${ }^{\mathrm{a}}$ & $0.3(1.0)$ & $0.7(1.1)$ \\
\hline Previous ICU days, mean (SD) ${ }^{\mathrm{a}}$ & $2.3(5.4)$ & $2.0(5.0)$ \\
\hline No CPR directive at admission, $n(\%)$ & $299(19.4)$ & $1480(11.0)$ \\
\hline \multicolumn{3}{|l|}{ Most responsible diagnosis, $n(\%)$} \\
\hline Infection/sepsis & $349(22.6)$ & $2037(15.1)$ \\
\hline Respiratory failure & $289(18.8)$ & $2732(20.3)$ \\
\hline Trauma & $137(8.9)$ & $1388(10.3)$ \\
\hline Malignancy & $117(7.6)$ & $1283(9.5)$ \\
\hline Spontaneous intracranial hemorrhage & $99(6.4)$ & $1182(8.8)$ \\
\hline Stroke & $90(5.8)$ & $1073(8.0)$ \\
\hline Overdose/poisoning & $36(2.3)$ & $432(3.2)$ \\
\hline Renal failure & $41(2.6)$ & $399(3.0)$ \\
\hline Gastrointestinal bleeding & $57(3.7)$ & $321(2.4)$ \\
\hline Congestive heart failure & $104(6.7)$ & $409(3.0)$ \\
\hline Cardiac arrest & $22(1.4)$ & $188(1.4)$ \\
\hline Seizures/status epilepticus & $18(1.2)$ & $202(1.5)$ \\
\hline Diabetic ketoacidosis & $9(0.6)$ & $116(0.9)$ \\
\hline Other & $173(11.2)$ & $1711(12.7)$ \\
\hline
\end{tabular}

Abbreviations: $C P R$ cardiopulmonary resuscitation, ED emergency department, ICU intensive care unit, MODS Multiple Organ Dysfunction Score, $S D$ standard deviation

${ }^{a}$ Only including patients with previous visits to the Ottawa Hospital 
Table 2 Outcomes of ICU patients $(n=15,014)$ with and without new-onset atrial fibrillation (NOAF)

\begin{tabular}{|c|c|c|c|c|}
\hline Characteristic & $\begin{array}{l}\text { New-onset atrial } \\
\text { fibrillation }(n=1541)\end{array}$ & $\begin{array}{l}\text { No atrial fibrillation } \\
(n=13,473)\end{array}$ & $\begin{array}{l}\text { Adjusted odds } \\
\text { ratio }^{c}(95 \% \mathrm{Cl})\end{array}$ & $P$ value \\
\hline In-hospital mortality, n (\%) & $576(37.4)$ & $4034(29.9)$ & $1.02(0.97-1.08)$ & 0.31 \\
\hline Disposition, $n(\%)^{a}$ & & & $0.95(0.88-1.09)$ & 0.57 \\
\hline Home & $562(58.2)$ & $6230(66.0)$ & & \\
\hline Long-term care center & $403(41.8)$ & $3209(34.0)$ & & \\
\hline $\begin{array}{l}\text { Time to NOAF development from hospital } \\
\text { admission, days, median (IQR) }\end{array}$ & $1(1-3)$ & - & & \\
\hline Persistent atrial fibrillation, $n(\%)^{\mathrm{b}}$ & $345(22.4)$ & - & & \\
\hline ICU length of stay, days, median (IQR) & $7(4-14)$ & $6(2-9)$ & & $<0.001$ \\
\hline Hospital length of stay, days, median (IQR) & $14(8-29)$ & $12(4-25)$ & & $<0.001$ \\
\hline Ventilator-free days, median (IQR) & $6(3-8)$ & $6(4-10)$ & & 0.03 \\
\hline Readmission to ICU during hospitalization, $n(\%)$ & $225(14.6)$ & $1670(12.4)$ & $1.04(0.94-1.11)$ & 0.27 \\
\hline Readmission within 30 days from discharge, $n(\%)^{\mathrm{a}}$ & $294(30.5)$ & $2426(25.7)$ & $1.08(0.87-1.19)$ & 0.13 \\
\hline
\end{tabular}

Abbreviations: ICU intensive care unit, IQR interquartile range, MODS Multiple Organ Dysfunction Score, SD standard deviation

aOnly includes patients surviving to discharge $(n=10,404)$

${ }^{\mathrm{b}}$ Defined as presence of any atrial fibrillation following $24 \mathrm{~h}$ of treatment

${ }^{\mathrm{c}}$ Ratio of NOAF to patients with no atrial fibrillation

mortality in critically ill adults, although an association was demonstrated in subgroups of patients with suspected infection, sepsis, and septic shock. Among patients who developed NOAF, predictors of hospital mortality included increasing age, severity of illness, history of $\mathrm{CHF}$, and sustained AF following treatment.
Patients with NOAF had prolonged ICU and hospital LOS, and NOAF was a predictor of increased total costs. Mechanical ventilation, renal replacement therapy, and use of antiarrhythmic therapy were significant predictors of total cost in NOAF patients. Taken together, our study identifies important novel associations between

Table 3 Multivariable logistic regression model for hospital mortality for patients with suspected infection $(n=4837)$

\begin{tabular}{|c|c|c|c|}
\hline Variable & Odds ratio & $95 \% \mathrm{Cl}$ & $P$ value \\
\hline Age (per 5 years) & 1.06 & $1.03-1.11$ & $<0.001$ \\
\hline Male gender & 1.04 & $0.93-1.14$ & 0.41 \\
\hline New-onset atrial fibrillation & 1.21 & $1.08-1.37$ & $<0.001$ \\
\hline MODS (per 1 point) & 1.07 & $1.04-1.10$ & $<0.001$ \\
\hline \multicolumn{4}{|l|}{ Comorbidities } \\
\hline Congestive heart failure & 1.28 & $1.04-1.55$ & $<0.01$ \\
\hline Peripheral vascular disease & 1.05 & $0.83-1.20$ & 0.65 \\
\hline Hypertension & 0.97 & $0.85-1.08$ & 0.48 \\
\hline Chronic obstructive pulmonary disease & 1.06 & $1.03-1.09$ & $<0.01$ \\
\hline Diabetes mellitus & 1.04 & $0.90-1.17$ & 0.22 \\
\hline Chronic kidney disease & 1.08 & $0.97-1.19$ & 0.10 \\
\hline Liver disease & 1.14 & $1.06-1.23$ & $<0.01$ \\
\hline Alcohol misuse & 0.97 & $0.88-1.15$ & 0.63 \\
\hline Elixhauser Comorbidity Score (per 1 point) & 1.02 & $1.01-1.04$ & $<0.01$ \\
\hline No CPR directive at ICU admission & 1.64 & $1.32-2.01$ & $<0.001$ \\
\hline \multicolumn{4}{|l|}{ Location prior to ICU admission } \\
\hline Hospital wards & Ref & & \\
\hline Emergency department & 1.16 & $0.91-1.30$ & 0.42 \\
\hline Operating room & 1.10 & $0.92-1.21$ & 0.31 \\
\hline Peripheral hospital & 0.96 & $0.84-1.13$ & 0.58 \\
\hline
\end{tabular}


Table 4 Resource utilization among ICU patients $(n=15,014)$ with and without new-onset atrial fibrillation (NOAF)

\begin{tabular}{|c|c|c|c|}
\hline Characteristic & New-onset atrial fibrillation $(n=1541)$ & No atrial fibrillation $(n=13,473)$ & $P$ value \\
\hline Invasive mechanical ventilation, $n(\%)$ & $843(54.7)$ & $7119(52.8)$ & 0.16 \\
\hline Invasive mechanical ventilation days, median (IQR) & $5(3-6)$ & $5(2-7)$ & 0.37 \\
\hline Non-invasive mechanical ventilation, $n(\%)$ & $256(16.6)$ & $2358(17.5)$ & 0.38 \\
\hline Non-invasive mechanical ventilation days, median (IQR) & $1(1-2)$ & $1(1-2)$ & 0.15 \\
\hline Vasoactive medication, $n$ (\%) & $991(64.3)$ & $8245(61.2)$ & 0.02 \\
\hline Vasoactive medication days, median (IQR) & $5(3-9)$ & $5(2-10)$ & 0.11 \\
\hline Arterial line, $n(\%)$ & $915(59.4)$ & $8407(62.4)$ & 0.02 \\
\hline Arterial line days, median (IQR) & $5(4-10)$ & $5(4-9)$ & 0.36 \\
\hline Renal replacement therapy, $n(\%)$ & $304(19.7)$ & $2411(17.9)$ & 0.18 \\
\hline Renal replacement therapy days, median (IQR) & $4(2-9)$ & $4(2-9)$ & 0.57 \\
\hline NEMS/day, mean (SD) & $26.3(7.2)$ & $25.1(8.0)$ & 0.35 \\
\hline \multicolumn{4}{|l|}{ Transfusion products, $n(\%)$} \\
\hline Packed red blood cells & $592(38.4)$ & $5079(37.7)$ & 0.58 \\
\hline Platelets & $104(6.7)$ & $688(5.1)$ & $<0.01$ \\
\hline Fresh frozen plasma & $85(5.5)$ & $835(6.2)$ & 0.29 \\
\hline Albumin & $735(47.7)$ & $6898(51.2)$ & $<0.01$ \\
\hline \multicolumn{4}{|l|}{ Treatment strategy, $n$ (\%) } \\
\hline Beta-blocker, calcium channel blocker, or digoxin & $644(41.8)$ & - & \\
\hline Antiarrhythmic & $747(48.5)$ & - & \\
\hline Electrical cardioversion & $22(1.4)$ & - & \\
\hline Combination & $128(8.3)$ & - & \\
\hline
\end{tabular}

Abbreviations: IQR interquartile range, NEMS Nine Equivalents of Nursing Manpower Scale, SD standard deviation

Table 5 Costs among ICU patients $(n=15,014)$ with and without new-onset atrial fibrillation (NOAF)

\begin{tabular}{|c|c|c|c|}
\hline Characteristic & New-onset atrial fibrillation $(n=1541)$ & No atrial fibrillation $(n=13,473)$ & $P$ value \\
\hline Total costs, \$, mean (SD) & $50,799(38,473)$ & $41,832(38,772)$ & $<0.001$ \\
\hline Total direct costs, \$, mean (SD) & $37,392(31,538)$ & $30,231(32,922)$ & $<0.01$ \\
\hline Total cost per survivor, $\$$ & 81,120 & 59,710 & \\
\hline \multicolumn{4}{|l|}{ Attributable costs, $\$$, mean (SD) } \\
\hline Food services & $1046(1104)$ & $937(1032)$ & 0.37 \\
\hline Health professionals (non-physician or nursing) & $2859(2175)$ & $2957(2.250)$ & 0.45 \\
\hline Laboratory & $2144(1910)$ & $1877(1823)$ & $<0.01$ \\
\hline Medical imaging & $1438(1672)$ & $1401(1573)$ & 0.29 \\
\hline Pharmacy & $3582(3288)$ & $2893(3092)$ & $<0.001$ \\
\hline Respiratory therapy & $3944(6188)$ & $3748(6229)$ & 0.48 \\
\hline Nursing & $39,492(36,493)$ & $28,344(31,302)$ & $<0.001$ \\
\hline \multicolumn{4}{|l|}{ ICU costs, $\$$, mean (SD) } \\
\hline Total costs & $41,303(37,743)$ & $28,298(41,393)$ & $<0.001$ \\
\hline Direct costs & $31,874(30,838)$ & $21,323(21,504)$ & $<0.001$ \\
\hline Indirect costs & 9239 (8482) & 7367 (8043) & 0.08 \\
\hline
\end{tabular}


NOAF and outcomes among critically ill patients, and also describes the economic impact of NOAF.

Hospital mortality among critically ill adults is high, and therefore, identification of prognostic factors associated with increased risk can be helpful to clinicians in escalating or tailoring therapy. Identification of these factors may also be helpful in discussions with patients and families regarding goals of care. NOAF is often thought to be a marker of illness severity [3]; however, the evidence examining the association between NOAF and hospital mortality remains uncertain [4]. In our large cohort of critically ill adults, we did not find such an association. However, evaluation of subgroups of patients with suspected infection, sepsis, and septic shock did find an independent association between NOAF and hospital mortality potentially suggesting that the consequences of NOAF in the patient with sepsis may differ from other populations.

Important physiologic changes occur during sepsis that make the atrial substrate vulnerable to NOAF [33], and patients with sepsis have a nearly sixfold risk of developing $\mathrm{AF}$, as compared to other populations [14]. Our findings identifying an independent association between NOAF and mortality from sepsis are supportive of existing literature, and potentially suggest that survival in this population may be improved through the prevention and treatment of NOAF [34]. Importantly, unlike previous studies, we defined sepsis and septic shock using the most recent Sepsis-3 definitions, indicating that NOAF has potential implications in these populations, and demonstrate an interaction between the presence of NOAF and sepsis. In keeping with the Sepsis-3 focus of sepsis as infection with concomitant organ dysfunction, NOAF may indeed represent sepsis-defining cardiac dysfunction [35]. As such, NOAF during sepsis might mediate mortality and may not simply be a marker of illness severity, as is seen in other disease processes [36].

If NOAF does represent a marker of illness severity, then its presence may be considered an important indicator of deterioration among critically ill patients. Therefore, identification of factors associated with mortality among ICU patients who develop NOAF remains an important area of ongoing research [4]. Unsurprisingly, a history of heart failure was associated with hospital mortality among patients with NOAF in our cohort, suggesting that these patients may be more susceptible to the hemodynamic effects of NOAF. Our results also found that sustained AF following $24 \mathrm{~h}$ of treatment was also associated with higher hospital mortality. Therefore, sustained AF may represent a particular ominous marker of illness severity among critically ill adults, and clinicians should act cautiously in those patients with NOAF and persisting AF.

We additionally evaluated the association between NOAF and hospital resource use and cost. Identification of factors associated with such outcomes remains an important focus in critical care research [11]. Few differences were found with regard to resource utilization between patients with and without NOAF. However, patients with NOAF did have prolonged ICU and hospital LOS, which translated into higher costs. The presence of NOAF was also a significant predictor of costs among our cohort, and this was independent of other important factors more commonly associated with cost, including renal replacement therapy and mechanical ventilation [37]. This prolonged LOS was also manifested in increased laboratory, pharmacy, and nursing costs. Despite higher costs, patients with NOAF had higher unadjusted mortality, which translated into significant differences in cost per survivor (a proxy indicator of cost-effectiveness).

Among patients with NOAF, treatment with antiarrhythmic medication (as compared to beta-blockers, calcium channel blockers, or digoxin) was associated with higher cost, but decrease in mortality. While this study was not designed to test the efficacy of therapeutic agents for NOAF, the little evidence that exists on this topic seems to suggest no beneficial effect of any particular agent $[3,4]$. This is in keeping with our results. We did not find evidence of difference in mortality associated with antiarrhythmic agents, but did note increased cost. This is likely attributable to the expense of these drugs [38], and the fact that they often cannot be administered outside of a monitored setting and therefore may prolong ICU LOS. However, it must be stressed that the efficacy of these agents can only be appropriately tested in a randomized trial, and while equipoise exists, decisions related to agents for treatment of NOAF must be made on a case-by-case basis.

We used a large multicenter database of patients with prospective identification of NOAF, and provide novel data related to hospital mortality, resource utilization, and cost. We also closely followed recommendations for control of confounding in observational studies [30]. However, our study has important limitations. Most importantly, our database lacks the granularity to investigate other potential factors that may influence outcome from NOAF, such as underlying cardiac function, pulmonary artery catheterization, rate of AF, timing of $\mathrm{AF}$ (particularly in relation to onset of critical illness), use of anticoagulation, and incidence of other arrhythmias. Some outcome data, such as incidence of stroke, were not available. We additionally excluded patients with existing AF on the basis of known or documented AF, but it is possible that patients may have had pre-existing AF and not known, due to absence of symptoms [39]. Overall, this lack of granularity represents an important limitation in our study. Second, patients were included on the basis of prospective identification by nursing staff. While similar methods have been used at other institutions [40], it is possible that cases of NOAF were missed using this methodology, particularly if AF was brief and transiently 
resolved. Third, we only had data related to outcomes prior to hospital death or discharge. Existing data suggest deleterious long-term outcomes in patients who develop NOAF during critical illness [15, 41]. Unfortunately, we were unable to evaluate this in our cohort. Finally, while our data are derived from two hospitals, they exist within the same city and therefore are susceptible to bias from local practices.

\section{Conclusions}

While NOAF was not associated with hospital mortality among all critically ill patients, it was associated with mortality in subgroups of patients with suspected infection, sepsis, and septic shock. Among patients with NOAF, sustained AF was associated with higher risk of hospital mortality. Finally, patients with NOAF had higher costs than patients without NOAF, and NOAF was a predictor of increased total costs among all ICU patients.

\section{Supplementary information}

Supplementary information accompanies this paper at https://doi.org/10. 1186/s13054-020-2730-0.

Additional file 1 : Table S1. Multivariable Logistic Regression Model for hospital mortality for entire study cohort $(n=15,014)$. Multivariable Logistic Regression Model for hospital mortality for entire study cohort $(n=15,014)$.

Additional file $\mathbf{2}$ : Table S2. Multivariable Logistic Regression Model for hospital mortality for patients with sepsis $(n=1944)$. Multivariable Logistic Regression Model for hospital mortality for patients with sepsis $(n=1944)$.

Additional file 3 : Table S3. Multivariable Logistic Regression Model for hospital mortality for patients with septic shock $(n=1286)$. Multivariable Logistic Regression Model for hospital mortality for patients with septic shock $(n=1286)$

Additional file 4 : Table S4. Multivariable Logistic Regression Model for hospital mortality for entire study cohort $(n=15,014)$, including interaction terms. Multivariable Logistic Regression Model for hospital mortality for entire study cohort $(n=15,014)$, including interaction terms.

Additional file 5 : Table S5. Multivariable Logistic Regression Model for hospital mortality among patients with new-onset atrial fibrillation ( $n=$ 1541). Multivariable Logistic Regression Model for hospital mortality among patients with new-onset atrial fibrillation $(n=1541)$.

Additional file $\mathbf{6}$ : Table S6. Generalized Linear Model with gamma distribution and log link for total cost for entire study cohort $(n=15,014)$. Generalized Linear Model with gamma distribution and log link for total cost for entire study cohort $(n=15,014)$.

Additional file $\mathbf{7}$ : Table S7. Generalized Linear Model with gamma distribution and log link for total cost for patients with new-onset atrial fibrillation $(n=15,014)$. Generalized Linear Model with gamma distribution and log link for total cost for patients with new-onset atrial fibrillation $(n=15,014)$.

\section{Abbreviations}

AF: Atrial fibrillation; aOR: Adjusted odds ratio; CPR: Cardiopulmonary resuscitation; CR: Cost ratio; ICD-10: International Classifications of Diseases, Version 10; ICU: Intensive care unit; IQR: Interquartile range; LOS: Length of stay; MODS: Multiple Organ Dysfunction Score; NOAF: New-onset atrial fibrillation; SD: Standard deviation; Sepsis-3: Third International Consensus Definitions for Sepsis and Septic Shock; SOFA: Sequential Organ Failure Assessment

\section{Authors' contributions}

SMF, RM, BH, BR, and KK designed the study. SMF and KK gathered the data. SMF, RM, BH, BR, LM, AJW, MHM, TS, PD, FDR, PT, and KK analyzed the data, interpreted the data, and wrote the manuscript. All authors read and approved the final manuscript.

\section{Funding}

None received.

\section{Availability of data and materials}

The datasets generated and analyzed are not publicly available due to patient privacy considerations, but are available from the corresponding author on reasonable request.

Ethics approval and consent to participate

Ethics approval for this study was obtained from the Ottawa Health Sciences Research Ethics Board.

Consent for publication

Not applicable.

\section{Competing interests}

The authors declare that they have no competing interests.

\section{Author details}

'Division of Critical Care, Department of Medicine, University of Ottawa Ottawa, ON, Canada. ${ }^{2}$ Department of Emergency Medicine, University of Ottawa, Ottawa, ON, Canada. ${ }^{3}$ Division of Cardiology, University of Ottawa Heart Institute, Ottawa, ON, Canada. ${ }^{4}$ Department of Medicine, Division of Critical Care, McMaster University, Hamilton, ON, Canada. ${ }^{5}$ Department of Health Research Methods, Evidence, and Impact, McMaster University, Hamilton, ON, Canada. ${ }^{6}$ Interdepartmental Division of Critical Care Medicine, University of Toronto, Toronto, ON, Canada. ${ }^{7}$ Department of Medicine, Sinai Health System, Toronto, ON, Canada. ${ }^{8}$ Department of Medicine, The Pulmonary Center, Boston University School of Medicine, Boston, MA, USA ${ }^{9}$ Center for Implementation and Improvement Sciences, Boston University School of Medicine, Boston, MA, USA. ${ }^{10}$ Department of Intensive Care, Copenhagen University Hospital Righospitalet, Copenhagen, Denmark. ${ }^{11}$ Electrophysiology Service, Hôpital Cardiologique du Haut-Lévêque, Centre Hospitalier Universitaire de Bordeaux, Bordeaux-Pessac, France. ${ }^{12}$ L'Institut de Rythmologie et Modélisation Cardiaque, Université de Bordeaux,

Bordeaux-Pessac, France. ${ }^{13}$ Clinical Epidemiology Program, Ottawa Hospital Research Institute, Ottawa, ON, Canada. ${ }^{14}$ Bruyere Research Institute, Ottawa, ON, Canada. ${ }^{15}$ Division of Palliative Care, Department of Medicine, University of Ottawa, Ottawa, ON, Canada. ${ }^{16}$ School of Epidemiology and Public Health, University of Ottawa, Ottawa, ON, Canada. ${ }^{17}$ Institut du Savoir Montfort, Ottawa, ON, Canada.

Received: 4 November 2019 Accepted: 5 January 2020

Published online: 13 January 2020

\section{References}

1. Lloyd-Jones DM, Wang TJ, Leip EP, Larson MG, Levy D, Vasan RS, D'Agostino RB, Massaro JM, Beiser A, Wolf PA, et al. Lifetime risk for development of atria fibrillation: the Framingham Heart Study. Circulation. 2004;110(9):1042-6.

2. Benjamin EJ, Wolf PA, D'Agostino RB, Silbershatz H, Kannel WB, Levy D. Impact of atrial fibrillation on the risk of death: the Framingham Heart Study. Circulation. 1998;98(10):946-52.

3. Bosch NA, Cimini J, Walkey AJ. Atrial fibrillation in the ICU. Chest. 2018; 154(6):1424-34.

4. Wetterslev M, Haase N, Hassager C, Belley-Cote EP, Mclntyre WF, An Y, Shen J, Cavalcanti AB, Zampieri FG, Guimaraes HP, et al. New-onset atrial fibrillation in adult critically ill patients: a scoping review. Intensive Care Med. 2019;45(7):928-38.

5. Annane D, Sebille V, Duboc D, Le Heuzey JY, Sadoul N, Bouvier E, Bellissant E. Incidence and prognosis of sustained arrhythmias in critically ill patients. Am J Respir Crit Care Med. 2008;178(1):20-5.

6. Kanji S, Williamson DR, Yaghchi BM, Albert M, McIntyre L. Epidemiology and management of atrial fibrillation in medical and noncardiac surgical adult intensive care unit patients. J Crit Care. 2012;27(3):326.e321-8. 
7. Klein Klouwenberg PM, Frencken JF, Kuipers S, Ong DS, Peelen LM, van Vught LA, Schultz MJ, van der Poll T, Bonten MJ, Cremer OL. Incidence, predictors, and outcomes of new-onset atrial fibrillation in critically ill patients with sepsis. A cohort study. Am J Respir Crit Care Med. 2017;195(2):205-11.

8. Moss TJ, Calland JF, Enfield KB, Gomez-Manjarres DC, Ruminski C, DiMarco JP, Lake DE, Moorman JR. New-onset atrial fibrillation in the critically ill. Crit Care Med. 2017:45(5):790-7.

9. Shaver CM, Chen W, Janz DR, May AK, Darbar D, Bernard GR, Bastarache JA, Ware LB. Atrial fibrillation is an independent predictor of mortality in critically ill patients. Crit Care Med. 2015;43(10):2104-11.

10. Carrera P, Thongprayoon C, Cheungpasitporn W, lyer VN, Moua T. Epidemiology and outcome of new-onset atrial fibrillation in the medical intensive care unit. J Crit Care. 2016;36:102-6.

11. Kyeremanteng K, Downar J. Why is it so hard to stop doing things that are unwanted, non-beneficial, or unsustainable? Lancet Respir Med. 2019;7(7):558-60.

12. Stelfox HT, Bourgault AM, Niven DJ. De-implementing low value care in critically ill patients: a call for action-less is more. Intensive Care Med. 2019; 45(10):1443-1446.

13. Kyeremanteng K, Wan C, D'Egidio G, Neilipovitz D. Approach to economic analysis in critical care. J Crit Care. 2016;36:92-6.

14. Walkey AJ, Wiener RS, Ghobrial JM, Curtis LH, Benjamin EJ. Incident stroke and mortality associated with new-onset atrial fibrillation in patients hospitalized with severe sepsis. JAMA. 2011;306(20):2248-54.

15. Walkey AJ, Hammill BG, Curtis LH, Benjamin EJ. Long-term outcomes following development of new-onset atrial fibrillation during sepsis. Chest. 2014;146(5):1187-95.

16. Fernando SM, Reardon PM, Rochwerg B, Shapiro NI, Yealy DM, Seely AJE, Perry JJ, Barnaby DP, Murphy K, Tanuseputro P, et al. Sepsis-3 septic shock criteria and associated mortality among infected hospitalized patients assessed by a rapid response team. Chest. 2018;154(2):309-16.

17. Fernando SM, Reardon PM, Dowlatshahi D, English SW, Thavorn K, Tanuseputro P, Perry JJ, Rosenberg E, Wijdicks EF, Heyland DK, et al. Outcomes and costs of patients admitted to the ICU due to spontaneous intracranial hemorrhage. Crit Care Med. 2018;46(5):e395-403.

18. Fernando SM, Reardon PM, Mclsaac DI, Eagles D, Murphy K, Tanuseputro P, Heyland DK, Kyeremanteng K. Outcomes of older hospitalized patients requiring rapid response team activation for acute deterioration. Crit Care Med. 2018;46(12):1953-60.

19. Fernando SM, Mclsaac DI, Rochwerg B, Bagshaw SM, Muscedere J, Munshi L, Ferguson ND, Seely AJE, Cook DJ, Dave C, et al. Frailty and invasive mechanical ventilation: association with outcomes, extubation failure, and tracheostomy. Intensive Care Med. 2019;45(12):1742-52.

20. Singer M, Deutschman CS, Seymour CW, Shankar-Hari M, Annane D, Bauer M, Bellomo R, Bernard GR, Chiche JD, Coopersmith CM, et al. The third international consensus definitions for sepsis and septic shock (Sepsis-3). JAMA. 2016:315(8):801-10

21. Seymour CW, Liu VX, Iwashyna TJ, Brunkhorst FM, Rea TD, Scherag A, Rubenfeld G, Kahn JM, Shankar-Hari M, Singer M, et al. Assessment of clinical criteria for sepsis: for the third international consensus definitions for sepsis and septic shock (Sepsis-3). JAMA. 2016;315(8):762-74.

22. Shankar-Hari M, Phillips GS, Levy ML, Seymour CW, Liu VX, Deutschman CS, Angus DC, Rubenfeld GD, Singer M, Sepsis Definitions Task F. Developing a new definition and assessing new clinical criteria for septic shock: for the third international consensus definitions for sepsis and septic shock (Sepsis-3). JAMA. 2016;315(8):775-87.

23. Fernando SM, Mclsaac DI, Perry JJ, Rochwerg B, Bagshaw SM, Thavorn K, Seely AJE, Forster AJ, Fiest KM, Dave C, et al. Frailty and associated outcomes and resource utilization among older ICU patients with suspected infection. Crit Care Med. 2019;47(8):e669-76.

24. Elixhauser A, Steiner C, Harris DR, Coffey RM. Comorbidity measures for use with administrative data. Med Care. 1998;36(1):8-27.

25. Marshall JC, Cook DJ, Christou NV, Bernard GR, Sprung CL, Sibbald WJ. Multiple organ dysfunction score: a reliable descriptor of a complex clinical outcome. Crit Care Med. 1995;23(10):1638-52.

26. van Walraven C, Austin PC, Jennings A, Quan H, Forster AJ. A modification of the Elixhauser comorbidity measures into a point system for hospital death using administrative data. Med Care. 2009;47(6):626-33.

27. Fernando SM, Rochwerg B, Reardon PM, Thavorn K, Seely AJE, Perry J, Barnaby DP, Tanuseputro P, Kyeremanteng K. Emergency department disposition decisions and associated mortality and costs in ICU patients with suspected infection. Crit Care. 2018;22(1):172.
28. Ronksley PE, McKay JA, Kobewka DM, Mulpuru S, Forster AJ. Patterns of health care use in a high-cost inpatient population in Ottawa, Ontario: a retrospective observational study. CMAJ Open. 2015;3(1):E111-8.

29. Little J, Higgins JP, loannidis JP, Moher D, Gagnon F, von Elm E, Khoury MJ, Cohen B, Davey-Smith G, Grimshaw J, et al. Strengthening the reporting of genetic association studies (STREGA): an extension of the strengthening the reporting of observational studies in epidemiology (STROBE) statement. J Clin Epidemiol. 2009;62(6):597-608.e594.

30. Lederer DJ, Bell SC, Branson RD, Chalmers JD, Marshall R, Maslove DM, Ost DE, Punjabi NM, Schatz M, Smyth AR, et al. Control of confounding and reporting of results in causal inference studies. Guidance for authors from editors of respiratory, sleep, and critical care journals. Ann Am Thorac Soc. 2019;16(1):22-8

31. Blough DK, Ramsey SD. Using generalized linear models to assess medical care costs. Health Serv Outcome Res Methodol. 2000;1(2):185-202.

32. Gregori D, Petrinco M, Bo S, Desideri A, Merletti F, Pagano E. Regression models for analyzing costs and their determinants in health care: an introductory review. Int J Qual Health Care. 2011;23(3):331-41.

33. Meierhenrich R, Steinhilber E, Eggermann C, Weiss M, Voglic S, Bogelein D, Gauss A, Georgieff M, Stahl W. Incidence and prognostic impact of newonset atrial fibrillation in patients with septic shock: a prospective observational study. Crit Care. 2010;14(3):R108.

34. Walkey AJ, McManus D. When rhythm changes cause the blues: new-onset atrial fibrillation during sepsis. Am J Respir Crit Care Med. 2017;195(2):152-4.

35. Bosch NA, Massaro JM, Winter MR, Quinn EK, Chon KH, DD MM, Walkey AJ. New-onset atrial fibrillation as a sepsis defining organ failure. Ann Am Thorac Soc. 2019;16(10):1332-1334.

36. Walkey AJ, Adhikari NKJ, Day AG, Radermacher P, Asfar P, Lamontagne F. Mediation analysis of high blood pressure targets, arrhythmias, and shock mortality. Am J Respir Crit Care Med. 2019;199(6):802-5.

37. Dasta JF, McLaughlin TP, Mody SH, Piech CT. Daily cost of an intensive care unit day: the contribution of mechanical ventilation. Crit Care Med. 2005; 33(6):1266-71.

38. Mark DB, Nelson CL, Anstrom KJ, Al-Khatib SM, Tsiatis AA, Cowper PA, Clapp-Channing NE, Davidson-Ray L, Poole JE, Johnson G, et al. Costeffectiveness of defibrillator therapy or amiodarone in chronic stable heart failure: results from the Sudden Cardiac Death in Heart Failure Trial (SCDHeFT). Circulation. 2006;114(2):135-42.

39. Page RL, Tilsch TW, Connolly SJ, Schnell DJ, Marcello SR, Wilkinson WE, Pritchett EL. Asymptomatic or "silent" atrial fibrillation: frequency in untreated patients and patients receiving azimilide. Circulation. 2003;107(8):1141-5.

40. Ding EY, Albuquerque D, Winter M, Binici S, Piche J, Bashar SK, Chon K, Walkey AJ, McManus DD. Novel method of atrial fibrillation case identification and burden estimation using the MIMIC-III electronic health data set. J Intensive Care Med. 2019;34(10):851-7.

41. Kim K, Yang PS, Jang E, Yu HT, Kim TH, Uhm JS, Kim JY, Sung JH, Pak HN, Lee $\mathrm{MH}$, et al. Long-term impact of newly diagnosed atrial fibrillation during critical care: a South Korean nationwide cohort study. Chest. 2019;156(3): 518-528.

\section{Publisher's Note}

Springer Nature remains neutral with regard to jurisdictional claims in published maps and institutional affiliations.

Ready to submit your research? Choose BMC and benefit from:

- fast, convenient online submission

- thorough peer review by experienced researchers in your field

- rapid publication on acceptance

- support for research data, including large and complex data types

- gold Open Access which fosters wider collaboration and increased citations

- maximum visibility for your research: over $100 \mathrm{M}$ website views per year

At BMC, research is always in progress.

Learn more biomedcentral.com/submissions 